\title{
Development of surgical palliative care as a field and community building in palliative care: past, present, and future directions
}

\author{
Susan D. McCammon ${ }^{1}$, Melissa Red Hoffman ${ }^{2}$ \\ ${ }^{1}$ Departments of Otolaryngology - Head and Neck Surgery and Internal Medicine, Division of Gerontology, Geriatrics and Palliative Care, The \\ University of Alabama at Birmingham, Birmingham, AL, USA; ${ }^{2}$ Department of Surgery, University of North Carolina, Attending Acute Care \\ Surgeon, Mission Hospital, Asheville, NC, USA \\ Contributions: (I) Conception and design: Both authors; (II) Administrative support: SD McCammon; (III) Provision of study materials or patients: \\ None; (IV) Collection and assembly of data: Both authors; (V) Data analysis and interpretation: Both authors; (VI) Manuscript writing: Both authors; \\ (VII) Final approval of manuscript: Both authors. \\ Correspondence to: Susan D. McCammon, MFA, MD, FACS, FAAHPM. John W. Poynor Professor in Otolaryngology, Professor, Departments \\ of Otolaryngology - Head and Neck Surgery and Internal Medicine, Division of Gerontology, Geriatrics and Palliative Care, The University of \\ Alabama at Birmingham, Faculty Office Tower 1155, 1720 2nd Avenue South, Birmingham, AL 35294-3412, USA. Email: smccammon@uabmc.edu; \\ Melissa Red Hoffman, MD, FACS. Adjunct Assistant Professor, Department of Surgery, University of North Carolina, Attending Acute Care \\ Surgeon, Mission Hospital, 509 Biltmore Avenue, Asheville, NC 28804, USA. Email: Redhoffman@gmail.com.
}

\begin{abstract}
The professionalization of hospice and palliative medicine has been well documented, as has its associated rise to specialty status. The movement to formalize hospice and palliative medicine in the United States included ten sponsoring boards for initial certification through a practice pathway. Thus, it began with the potential for subspecialty interests, advocacy, and training. This review will examine the emergence of surgical palliative care as a field within hospice and palliative medicine as well as its unique place within the specialty of surgery, where it is sometimes hailed as an inherent, historically present body of knowledge and skill, and just as often, remarked upon as an ahistorical oxymoron. The phases of formation, early adoption, popularization, and normalization will be described and illustrated by the benchmarks of formal education requirements, board eligibility and certification, and professional relationships fostered by medical societies and online communities. Community building in palliative care must acknowledge the diversity of its constituents and the differences in subspecialty identity formation and sources of professional credibility and legitimacy. Metaphors for practitioners of surgical palliative care range from the rarity of the unicorn to the swarm intelligence principles of the beehive. Future directions include facing the questions about the role of specialty training and practice in surgical palliative care compared to renewed emphasis on palliative principles in general surgical training and practice.
\end{abstract}

Keywords: Palliative; professionalism; specialization; surgery

Submitted Feb 11, 2021. Accepted for publication Oct 19, 2021.

doi: 10.21037/apm-21-373

View this article at: https://dx.doi.org/10.21037/apm-21-373

\section{Introduction}

Medical specialization emerged in the early twentieth century in the aftermath of the Flexner Report. With strong professional, organizational and political connotations, specialization has been described as the primary organizing principle for medicine in the twentieth century (1). It illustrates the expansion of expertise and specialized knowledge beyond what could be mastered by a general practitioner; the perceived and then actual need for hospitals as centers for technology and disease management; and the momentum of scientific discovery that supported medical schools and advanced training programs. One hundred years later, at the end of the twentieth century, this organization led to debates over the roles of generalist and specialist 
practitioners, identification of gatekeepers for managed care organizations, and the impact of fragmentation on the quality of patient care. Today, medical specialization is characterized by disciplinary themes, such as genetics or informatics, which cut across traditional specialties and unite others. The development of new specialties is often captured at the intersection of other related specialties and formalized as the product of multiple sponsoring boards or certification of an added qualification.

Beyond a body of special knowledge, an aspiring medical specialty is built by its initial enthusiasts, its first experts, its early adopters. Often emerging in response to a perceived need in an existing specialty, a nascent specialty may begin with an organizing meeting and the formation of a Work Group or Task Force to assess needs and identify the potential contributions of their group. Such contributions may take the form of presentations at national meetings, the development of durable educational products such as curricula or textbooks, and the formalization of an ad boc working group into a standing committee within a related, recognized specialty. Beyond that, as a specialty differentiates and seeks autonomy, the icons of subspecialty recognition include periodic conferences, dedicated journals, additional committees and working groups that may coalesce into a formal medical specialty society. The ultimate markers of a medical specialty are recognition by a certifying board such as the American Board of Medical Specialties and the associated training requirements and certifying examination. Some have argued for the critical importance of an autonomous department in a medical school (2). Others have pointed to the power of governmental funding for research (3). Perhaps one of the strongest markers of a maturing specialty is internal debate, divergence and the negotiation of a strategic plan that benefits from such plurality. Beyond these practical signs of professionalization, medical specialties achieve gravitas and influence through their (successful) exercise of selfregulation and their (defended) claim to jurisdiction over an area of specialized knowledge or technical skill $(4,5)$. Long before these external markers of stature, young specialties began in conversations and shared interests and concerns. Individuals bring their passions and their histories, both personal and professional, into a fluid realm of opportunity and challenge.

The professionalization of hospice and palliative medicine has been well documented, as has its associated rise to specialty status (6-9). It was first recognized as a formal medical specialty in Great Britain in 1987 and in 1990 the World Health Organization provided a global definition of palliative care that emphasized its importance in both curative and non-curative scenarios and introduced the ideals of upstream and concurrent palliative care which remain important today (10). The movement to formalize hospice and palliative medicine in the United States included ten sponsoring boards for initial certification through a practice pathway. Thus, it began with the potential for subspecialty interests, advocacy, and training. This review will examine the emergence of surgical palliative care as a field within hospice and palliative medicine as well as its unique place within the specialty of surgery, where it is sometimes hailed as an inherent, historically present body of knowledge and skill, and just as often, remarked upon as an ahistorical oxymoron.

\section{Formation}

One of the catalysts for the prioritization of palliative care in American medicine was the growing conversation about physician aid in dying in the late 1990s. In 1997 the U.S. Supreme Court upheld two state laws prohibiting assisted suicide: Washington v. Glucksberg, 521 U.S. 702 [1997] and Vacco v. Quill, 521 U.S. 793 [1997]. In a powerful concurring opinion regarding Glucksberg and Vacco, Justice Sandra Day O'Connor placed palliative care as the crossing guard between physician aid in dying and intractable suffering. In her concurring opinion Justice O'Connor wrote that “...suffering patients have a constitutionally cognizable interest in obtaining relief from the suffering that they may experience in the last days of their lives" (11). These court cases explored the ground between the autonomous patient's right to refuse life-sustaining medical treatment even if discontinuing Such treatment would result in the patient's death as well as the doctrine of double effect when applied to intractable suffering and the potential use of proportional palliative sedation to the point of unconsciousness (12).

Many of these same issues came to the fore at the American College of Surgeons (ACS) Clinical Congress in 1997 during a day-long symposium on physician-assisted suicide chaired by Dr. Thomas Krizek. A vigorous discussion ensued with strong opinions voiced. One of the common values that became apparent in this discussion was the acute need for surgeons to better address both the physical and existential suffering of patients being treated for surgical disease. Two points of concurrence were: palliative care is important for surgical patients, and surgeons are not well 
prepared, cognitively, nor psychologically, to provide it. A call to action was issued and a work group was convened. The charge for this collaborative group was to identify opportunities for improvement in palliative care for surgical patients. For many, the first meeting of this group marks the origin of surgical palliative care as an important field of inquiry and practice.

The original nineteen members of the Surgical Palliative Care Workgroup are listed at the end of the first in a series of monthly articles on palliative care by the surgeon published in the Fournal of the American College of Surgeons $(\mathcal{F A C S})$ (13). This article was accompanied by the ACS statement on principles guiding care at the end of life which was developed by the ACS Committee on Ethics and approved by the board of regents at its February 1998 meeting. This statement has subsequently been revised and updated as the ACS Statement of Principles of Palliative Care, approved in 2005. This statement was described as an evolutionary step beyond the ACS 1998 Statement of Principles Guiding Care at the End of Life. It describes extending palliative care to a broad range of patients receiving surgical care (14). Comparable statements were emerging from existing medical specialties worldwide (15).

Led by Dr. Geoff Dunn, the initial meeting of what would eventually become the Surgical Palliative Care Workgroup took place during the ACS Clinical Congress in 2000, the Workgroup identified two initial priorities: to make surgeons aware of existing sources of information about palliative and end-of-life care already developed and validated by other disciplines, and to promote the application of palliative principles to surgical procedures and practices. These two priorities illustrate important elements of the emerging field of surgical palliative care. The Workgroup also sponsored a symposium entitled "Palliative Care by the Surgeon: Patient Selection and Management" which featured debate amongst surgeons Drs. C. James Carrico and Thomas J. Krizek and prominent palliative physician, Dr. Kathleen Foley. Their resolution was to "foster awareness, education, and research...in conjunction with surgical institutions" (13).

Two important characteristics of the Workgroup and its approach deserve particular mention. First, Workgroup members were well aware of the work of other disciplines and approached this expertise with openness and humility. The initial Workgroup and subsequent standing committee included leading non-surgeon pioneers of palliative care. Second, members acknowledged that palliative care for surgical patients, as well as palliative care delivered by surgeons is not the same as palliative care for patients outside the surgical arena, and that specific attention should be paid to the application of palliative principles to operations, surgical patients, and surgeons. One of the pervasive themes in literature about palliative care in surgery is the tension between the idea that the relief of suffering (the very definition of palliative care) is part of the core identity of the surgeon and the idea that palliative care is somehow alien or antithetical to the current surgical culture $(16,17)$. Here, at its outset, we can appreciate the collaborative approach and the willingness of this group of surgeons to adopt a "beginner's mind". At the same time, from its inception, these surgeons were grappling with the historical role of palliation in the surgeon's identity, and how to reclaim that legacy $(18,19)$.

The first formal meeting of the Surgical Palliative Care Workgroup was held on September 10, 2001. This Workgroup was jointly supported by the ACS and by competitive grants from the Robert Wood Johnson Foundation (RWJF) as part of its promoting excellence in end-of-life care, a national program dedicated to longterm changes to improve health care for dying people and their families. This supported the development of a White Paper on palliative care in surgery, continuing educational presentations such as the 3-hour symposium on "Palliative Care by the Surgeon: How to Do It", and importantly, the development of a palliative care curriculum for surgical residency programs. The work of the group was made accessible through a monthly series of articles published in the Fournal of the American College of Surgeons ( $7 A C S$ ) from 2001 to 2005 and the RWJF-funded state-of-the-science paper was published in 2003 (20). In this same year, the Workgroup transitioned from an externally funded ad hoc working group to a permanent part of the ACS Division of Education under the leadership of Ajit Sachdeva and was renamed as the ACS Palliative Care Task Force. In 2013, the Task Force assumed its current designation, the Committee on Surgical Palliative Care (CSPC). It now has sub-committees on education, research, patient quality outcomes, and advocacy. The invaluable support of ACS leaders and the resulting early activities of the CSPC have been recorded as have the many work products of the RWJF Promoting Excellence in End-of-Life-Care Workgroup (20,21).

This Formation phase of the field of surgical palliative care recognizes the cultural and political influences shaping palliative care at the end of the twentieth century; it acknowledges the support of existing professional and 
funding entities such as the ACS and the RWJF; and it honors the energy and perseverance of the individuals who saw the need, reached out to others with complementary strengths and interests, and shaped the early agenda of work priorities. It also illustrates the powerful influence that a small group of individuals can have on a developing field. Each of these individuals brings culture and bias from their "parent" specialty as well as their formative professional experiences. A thoughtful consideration of who else might have been at the table but was not, or divergent opinions that might have been voiced, but were not, is always prudent. The original working group comprised both senior and junior faculty, surgeons and non-surgeons, men, and women. Some were practicing surgeons while others were full-time palliative care physicians. Expertise in education and ethics was represented in addition to surgical practice and training. The general surgical subspecialties most aligned with the needs of patients facing serious illness or end of life included surgical oncology, trauma, and critical care surgery, and emergency general surgery. Related surgical fields such as otolaryngology, neurosurgery, urology, plastic surgery, and gynecology were also included. As the field has developed, through the American Academy of Hospice and Palliative Medicine (AAHPM), the input of other professionals in the perioperative setting has emerged: anesthesiology and operative nursing in particular, as well as the role of emergency medicine in anticipatory management of surgical patients. The professional identity formation of each of these groups is subtly and sometimes dramatically different and this embracement of transdisciplinary collaboration has been a hallmark of more recent medical specialization; however, it is always important to consider who was not at the table during this formation phase. There were no nurses or social workers, doctoral researchers or trainees, and no patients or survivors. It is interesting to contemplate how these stakeholder perspectives might have shaped or accelerated the development of the field in different ways.

The trajectory of professionalization is to move from a Call to Action to an ad hoc Workgroup to a standing committee. The ACS Committee on Surgical Palliative Care has moved forward on this path. Led initially by Dr. Geoff Dunn and now by Dr. Anne Mosenthal, this committee has provided the structure and resources for continued progress on and beyond the priorities initially identified by the Workgroup. With continued support from the ACS Division of Education, the CSPC has met biannually since 2003 and has focused its efforts on developing and propagating awareness, knowledge, and skills about palliative care to practicing surgeons in order to benefit patients with surgical disease. The CSPC's mission is to incorporate the precepts and techniques of palliative care into surgical clinical practice education, research, and advocacy (21). The Committee has presented panels and symposia at the Clinical Congress, developed two preconference courses, and inaugurated the annual Symposium for Research in Surgical Palliative Care which occurs concurrent with the annual Clinical Congress. In terms of durable educational products, the committee contributed substantively to a guidebook for residents which is currently under revision for a second edition (22).

In addition to setting priorities and a working agenda for the field, these meetings and projects brought together a diverse group of surgeons with a common interest. While working together under the auspices of the ACS, many of the members of the Workgroup and the Committee were coming to terms with what their own practice of palliative care would or could look like. It is here that their course intersects with the professional and certifying authority of the AAHPM and the ABMS.

Throughout the early- and mid-aughts, Dr. Olga Jonassen - the first female chair of an academic department of surgery-was a critical supporter of surgical palliative care. As the director of the Division of Education for the ACS, she provided invaluable support and legitimacy to the field. It was Dr. Jonassen who advocated strongly for the American Board of Surgery to join other specialty boards in sponsoring board eligibility in hospice and palliative medicine.

\section{Early adopters: practice pathway}

Between 2008 and 2012, diplomates from ten sponsoring boards were able to complete the requirements of a specialty specific practice pathway to become eligible to take the certifying exam for hospice and palliative medicine produced by the American Board of Internal Medicine. These original sponsoring specialties included: internal medicine, anesthesiology, family medicine, physical medicine and rehabilitation, psychiatry, neurology, surgery, pediatrics, emergency medicine, radiology, and obstetrics and gynecology. Each specialty provided its own practice requirements for board eligibility, and each has its own origin narrative. The practice pathway proposed by the American Board of Surgery required four hundred hours of specialty specific practice in hospice and palliative medicine 
over at least 2 years, one hundred hours of participation in an interdisciplinary hospice and palliative medicine team, and active participation in the care of at least 50 terminally ill patients. Surgical subspecialties outside of general surgery and obstetrics and gynecology were allowed sponsorship by the ABS with approval of their original certifying board. Some early diplomates included neurosurgeons, head and neck surgical oncologists and urologists.

\section{Early adopters: fellowship training}

After 2012, board eligibility in HPM required completion of an ACGME-accredited fellowship. This is a typical pattern in the maturation of a new specialty: an early period that acknowledges the thought leaders and experts from other fields who will contribute to the teaching and research foundation of the newly formed specialty. With those foundational members of the specialty in place, program requirements for fellowships, accreditation, metrics and assessments, and expectations for standardized achievement as specialists in the field are possible $(1,7)$.

Currently, in order to sit for the HPM board exam, exam applicants must have completed at least 3 years of residency as well as a 1-year fellowship in HPM. Thus, surgical trainees may complete an ACGME-accredited HPM fellowship and take the HPM certifying exam following three progressive years of ACGME-accredited residency training. A guaranteed categorical residency position must be available to the individual following completion of HPM training. The certificate in HPM will not be awarded, however, until the individual has achieved primary certification. The ABS will also sponsor current diplomates of other ABMS surgical boards, provided their primary certifying board supports their application.

Much of the community building in the field of surgical palliative care has arisen around the perceived need for flexibility in training and alternative training pathways. A number of degree and nondegree programs are available for higher-level knowledge and skill acquisition in palliative care. These include the Harvard curriculum on Practicing Primary Palliative Care and Palliative Care Education and Practice, the Center to Advance Palliative Care (CAPC) resources, VitalTalk ${ }^{\mathrm{TM}}$ and Serious Illness communication courses. The Center for Palliative Care at Harvard Medical School offers the foundational course, Palliative Care Education and Practice (PCEP) which is a 6-month course with 12 days in person. Their Practical Aspects of Palliative Care is a virtual 1-day course that reviews primary palliative care skills. Another major educational effort is the Education in Palliative and End of Life Care (EPEC) program which offers a multimodule core curriculum with specialty adaptations for surgery as well as emergency medicine, pediatrics, veterans and caregivers. CAPC offers many online courses including training in pain management, communication, and advance care planning to members of participating institutions. The Four Seasons Consulting Group offers a palliative care immersion course which is a 5-day course with focus on all aspects of palliative care, including business. These programs provide an important range of training in both primary and specialist palliative care and models for "training the trainer". They do not, however, contribute directly to achieving board eligibility for hospice and palliative medicine. In contrast, The interprofessional palliative care certificate and master of science in palliative care at the University of Colorado Anschutz Medical Campus is designed to prepare healthcare providers and allied health professionals as palliative care community specialists to meet the needs of patients and families living with serious illness. It has established a platform for clinical experiential learning which may lead to board eligibility as a fellowship equivalent.

In a retrospective statistical analysis of cohort data from the American Association of Medical Colleges and the American Board of Medical Specialties, Berlin et al. have shown that of the 7,779 HPM certifications issued from 2008 to 2018, a dramatic decrease was noted after the requirement of fellowship training. Internal medicine and family medicine are the mainstream of diplomates; psychiatry, neurology and emergency medicine maintain a steady influx of candidates; surgical and perioperative specialties such as surgery, anesthesiology and OB/GYN are underrepresented. This is important because one of the hallmarks of palliative medicine's success is the fact that it has upstreamed itself into the need for a currently unavailable workforce (23-25). Surgical specialists cumulatively represented small numbers of fellowship entrants and only $3.4 \%(n=296)$ of HPM diplomates.

\section{Popularization}

Not surprisingly, since the charge of the original workgroup was to bring the principles of palliative care to the attention of surgeons and to bring surgeons to the active practice of competent palliative care, the interest in this field began to grow and the number of trainees and practitioners who found collegiality, opportunities for collaborative research, 
and the potential for a professional home burgeoned. Because of the infrastructure and resources committed to the ACS Committee on Surgical Palliative Care, it was not possible for everyone with relevant expertise or interest to be a member of the committee, even on a rotating basis. This need for professional interaction was met by the growing role of dedicated communities for the ACS, the AAHPM, and other specialty societies.

The AAHPM provides two levels of interprofessional community: Special Interest Groups, or SIGs, are approved with demonstration of $3 \%$ or more of total society membership; a Forum in contrast can be approved with 2\% or less of total society membership. Special Interest Groups, or SIGs, are a core organizing element of the AAHPM and represent what in many specialty societies would be committees. They have administrative support from the AAHPM, have their own elected governance, and have expectations for both engagement and productivity. The SIGs and the forums offer the benefit of open membership; they are not exclusive. One of the early vigorous conversations about the jurisdiction of surgical palliative care came about during the decision about what to name the SIG and to whom it would be targeted. The stakeholders voted to call it the Surgical and Perioperative Palliative Care SIG and the membership now comprises both physicians and medical trainees, with representation from general surgery, surgical subspecialties within and outside general surgery, anesthesiology, and multiple procedurebased specialties including interventional radiology as well as palliative care specialists $f$ with a particular interest in partnering with SIG members in collaborative projects of mutual interest (for example preoperative frailty screening and advance care planning efforts). There is, unfortunately, a lack of overlap and reciprocity with the Hospice and Palliative Nurses Association (HPNA), and therefore the constituency of the AAHPM and its SIGs do not reflect the interdisciplinary diversity of the field itself and this has stymied collaborative efforts. Of the ten sponsoring boards, three participate in the Surgical and Perioperative Care SIG (Anesthesiology, Surgery and OB/GYN). Four have recognizable linked SIGs for their original specialty (Psychosocial and Mental Health, Neuropalliative Care, Pediatrics, and Emergency Medicine). Radiology has a Forum for Palliative Radiation Oncology and PM\&R has a Forum for Rehabilitation. Certainly, there is the potential for abundant crossover between and among communities. Many members of the Surgical and Perioperative Care SIG are also active in the Cancer, ICU and Ethics SIGs. One increasingly popular form of communication for the SIGs is the AAHPM online communities which offer a moderated forum for discussion and collaboration. The Surgical and Perioperative Care SIG currently has 144 members and a robust election process each year for leadership succession.

For the ACS, a much older medical society, characterized as a formal College of Fellows, the committee structure is more entrenched in traditional categories and the emergence of special or interdisciplinary groups has been accommodated almost entirely by the provision of support for online communities. The Surgical Palliative Care Community has over two hundred members and like the AAHPM SIG, has open membership and thus welcomes participation by all, ranging from leaders in the field toas those who are exploring or observing a new area of interest. Almost all of the members of the AAHPM Surgical and Perioperative Care SIG who maintain membership in the ACS also belong to the Surgical Palliative Care Online Community and announcements and threads are routinely cross posted. Representatives of the ACS community are responsive to sharing ACS threads with the AAHPM SIG.

Beyond the structures provided by the ACS and the AAHPM for in-person and online community building, young leaders in the field have brought attention to surgical palliative care through webinars, podcasts, such as the Surgical Palliative Care Podcast (26), and social media presence, primarily on Twitter, at the handle@surgpallcare.

\section{Normalization}

With the foundational work of the early adopters established and publicized, attention turns to what the actual work looks like now. Who identifies with surgical palliative care? How are they incorporating it into their practice? How does it define their identity? Most importantly, how, if surgical palliative care as a field is to survive and thrive, do these first- and second-generation advocates ensure additional generations? It is fair also to ask at this point if surgical palliative care should persist as a separate field. This conundrum of existence teases most practitioners of palliative care: if we teach it well; if we believe this is something every physician should know; should we not be proud to sow the seeds of our own extinction? This article began with a reflection on the societal and sociological role of specialization within the medical profession. Eliminating the need for your professional role is not an accepted part of that historical narrative, yet current debates about the differentiation between generalist and specialist 
expectations, responsibilities and jurisdiction persist.

Communication is critical. The early visibility of the field will need to be maintained and updated. In addition to making colleagues and trainees aware of the importance and value of palliative care for surgical patients, the field and its leaders must provide mentorship and guidance towards realistic and viable career paths. In part to meet this need, the ACS and AAHPM communities established a mentorship connection program that links more senior practitioners with more junior practitioners who are seeking fellowship training and board certification or midcareer practitioners who are exploring a mid-career shift in emphasis.

The feasibility of adding to the field must be assessed. Early recognition of the challenges posed to young surgeons by a 1 -year fellowship following their completion of surgical training, led to advocacy for an embedded fellowship model. In this model, surgical residents who have completed 3 years of post-graduate training may match into an ACGME-approved palliative medicine fellowship to be done as part of their traditional "lab" years. Ideally this 1-year clinical fellowship would be paired with a year of research. The approval of the American Board of Surgery must be matched by the willingness of Palliative Medicine Fellowship Directors to interview and recruit candidates from fields outside the more dominant internal medicine and family medicine. Legitimate concerns have been voiced on both sides and conversation is ongoing to improve the preparation for trainees and trainers alike (7,27-30). Going forward, we may well ask: should there be more surgeons in palliative care fellowships? Or more palliative care in surgical fellowships? Or both?

\section{Future directions}

As we look to the future, it is illuminating to evaluate and appreciate the careers forged by the early adopters. Some of these are fully hybridized, with some time devoted to traditional surgical practice and some time devoted to fulltime palliative care. Examples of such careers divide time by days, weeks, or on service months. They divide location among inpatient palliative care units, inpatient consult services, inpatient hospice facilities, and outpatient provision of community-based palliative care. Some practitioners describe their practice as fully integrated; they are full-time surgeons who bring their expertise and skill in palliative care and communication into every patient encounter. Some of these integrated practitioners may identify their main contribution to the field of surgical palliative care as dedication to a funded research career pathway.

Common to all these pathways is the shared importance of demonstrating value by recognized metrics and addressing the challenges of fair compensation and professional credibility. Research itself is essential. The "specialized knowledge" of a medical specialty implies investment in the development of a unique knowledge base. In addition to bolstering the legitimacy of a special interest, research provides generalizable knowledge that can improve patient care far beyond the individual bedside. If a specialty is to survive and scale, it must have valid research. An organized gap analysis of research needs and articulation of a research agenda to meet those needs is a hallmark of a growing specialty. Such analyses and agendas have been published and updated by prominent research leaders, such as Zara Cooper, Fabian Johnston, and others (31,32).

As any field grows, it diversifies. A healthy fertile field encourages that diversification and welcomes new ideas even if divergent from its original charge or vision. Surgical palliative care has achieved national and international recognition as an important subset of both palliative medicine and surgery. Whether it will further differentiate into an independent specialty, whether it should, remains to be seen. The culmination of the first two decades of work in this field is the landmark text, Surgical Palliative Care, 2nd ed., edited by Drs. Dunn and Mosenthal and published by Oxford University Press in 2019 (33). Multiple journals have dedicated entire issues to the theme of surgical palliative care, including Clinics in Geriatric Medicine: Surgery in the Geriatric Patient (February 2019), Fournal of Surgical Oncology: Palliative Care in Surgical Oncology (July 2019), Surgical Clinics of North America: Practicing Primary Palliative Care (October 2019) and AAHPM Quarterly: "From Surgery to Palliative Medicine - Six Stories". Perhaps most notable, is the award this year of the AAHPM Lifetime Achievement Award to Dr. Geoff Dunn, known respectfully and affectionately as "The Father of Surgical Palliative Care". Dr. Dunn is only the second surgeon to be awarded the Lifetime Achievement Award; the first was Dr. Balfour Mount in 2001.

\section{Discussion}

Surgeons who practice palliative medicine are often introduced by our palliative medicine colleagues as "unicorns", meaning that as surgeons practicing in their midst, we are singular. The Oxford English Dictionary 
defines unicorn as: (I) a mythical animal typically represented as a horse with a single straight horn projecting from its forehead; (II) something that is highly desirable but difficult to find or obtain.

The common usage of "unicorn" carries connotations that as a mythical beast, it does not exist in reality, or if it does it is rare, unique, that there may be only one. A fitting reply comes from the website (https://www. collectivenounslist.com) which has three options for a group of unicorns: "the collective noun-name for collection or a number of people or things-for Unicorn is not only a Blessing, but it can be Glory or Marvel as well. Which means that a Group of Unicorns can easily be called "Glory of Unicorns" or "Marvel of Unicorns".

The process of becoming a recognized medical subspecialty has several benchmarks: formal training requirements, board certification, a society, an annual meeting, an official journal. hospice and palliative medicine has followed this pathway and surgical palliative care has reaped many of its benefits of fellowship and professional affirmation.

The idea for an open membership society for surgical palliative care was conceived during a dinner at the 2019 American College of Surgeons Clinical Congress. Founded in 2020 by Drs. Red Hoffman, Buddy Marterre and Pringl Miller-all surgeons board certified in hospice and palliative medicine-SPCS is the first and only professional society dedicated to the practice of Surgical Palliative Care. Modeled on the interdisciplinary palliative care team and inspired by Buddy's work as a beekeeper, the Society is structured in a non-hierarchical manner (like a bee colony!) and aims to foster community and fellowship amongst its members by affirming that all healthcare professionals involved in the care of surgical patients, including students and trainees, are welcome to join and to participate (34).

The specialty of hospice and palliative medicine in general, and the field of surgical palliative care specifically, are characterized by an interlocking set of paradoxes. The specialty arose out of perceived gaps in the care of patients with serious illness, including but not exclusively those approaching death. Throughout its professionalization, Palliative medicine has been faced with the definitional question: isn't this what medicine is really supposed to be? Shouldn't all physicians practice medicine like this? In many ways, the specialty's answer was "Yes...but." It should be like that, but it is not. Specialized palliative medicine promised to bring the full focus and power of evidence- based scientific medicine to bear on the elements of care left neglected by the full focus and power of evidence based scientific medicine. Critics have faulted specialist palliative medicine for medicalizing the last realm of humanism in medicine (35-38). The distinction between generalist and specialist palliative care arose partially in response to such critiques (39).

One of the ironies of surgical palliative care is the acknowledgement by the 1997 ACS Symposium that in surgery “our 'successes' since the Second World War had dimmed our collective memory of our original calling to relieve suffering and contributed to the atrophy of our capacity to mitigate it" (33).

Finally, the principle of nonabandonment is one that is often identified as the core moral value of the practice of surgery. The literature of palliative care further explored this concept by questioning if bringing a patient to the point of near death, suspended only by life sustaining technologies was just as much, if not more, a form of abandonment than denying additional heroic interventions. The underlying corollary of nonabandonment is accompaniment. We are learning, once again, to be present with our patients and also with our colleagues (40).

\section{Acknowledgments}

Funding: None.

\section{Footnote}

Provenance and Peer Review: This article was commissioned by the Guest Editors (Fabian M. Johnston and Ana Berlin) for the series "Palliative Care and Surgery" published in Annals of Palliative Medicine. The article has undergone external peer review.

Conflicts of Interest: Both authors have completed the ICMJE uniform disclosure form (available at https://apm. amegroups.com/article/view/10.21037/apm-21-373/coif). The series "Palliative Care and Surgery" was commissioned by the editorial office without any funding or sponsorship. The authors have no other conflicts of interest to declare.

Ethical Statement: The authors are accountable for all aspects of the work in ensuring that questions related to the accuracy or integrity of any part of the work are appropriately investigated and resolved. 
Open Access Statement: This is an Open Access article distributed in accordance with the Creative Commons Attribution-NonCommercial-NoDerivs 4.0 International License (CC BY-NC-ND 4.0), which permits the noncommercial replication and distribution of the article with the strict proviso that no changes or edits are made and the original work is properly cited (including links to both the formal publication through the relevant DOI and the license). See: https://creativecommons.org/licenses/by-nc-nd/4.0/.

\section{References}

1. Stevens R. American Medicine and The Public Interest: A History of Specialization. Updated Edition with a New Introduction ed. Berkeley, CA: University of California Press, 1998.

2. Halpern SA. American Pediatrics: The Social Dynamics of Professionalism, 1880-1980. Berkeley, CA: University of California Press, 1988.

3. Fye WB. American Cardiology: The History of a Specialty and Its College. Baltimore, MD: Johns Hopkins University Press, 1996.

4. Abbott A. The System of Professions: An Essay on the Division of Expert Labor. Chicago, IL: University of Chicago Press, 1988.

5. Evans JH. Defending the jurisdiction of the clinical ethicist. J Clin Ethics 2014;25:20-31.

6. Vanderpool HY. Palliative Care: The 400-Year Quest for a Good Death. Jefferson, NC: McFarland \& Company, Inc., 2015.

7. Quest TE, Marco CA, Derse AR. Hospice and palliative medicine: new subspecialty, new opportunities. Ann Emerg Med 2009;54:94-102.

8. Seymour J, Clark D, Winslow M. Pain and palliative care: the emergence of new specialties. J Pain Symptom Manage 2005;29:2-13.

9. Weissman DE. Journal of Palliative Medicine's new affiliation. J Palliat Med 2001;4:139-40.

10. World Health Organization. Cancer pain relief and palliative care. Geneva: World Health Organization, 1990.

11. U.S. Supreme Court. Vacco v. Quill. Wests Supreme Court Report 1997;117:2293-312.

12. McCammon SD, Piemonte NM. Continuous Sedation Until Death Should Not Be an Option of First Resort. J Clin Ethics 2015;26:132-42.

13. Dunn GP, Milch RA. Introduction and historical background of palliative care: where does the surgeon fit in? J Am Coll Surg 2001;193:325-8.
14. Task Force on Surgical Palliative care; Committee on Ethics. Statement of principles of palliative care. Bull Am Coll Surg 2005;90:34-5.

15. Cassel C, Foley K. Principles for care of patients at the end of life: an emerging consensus among the specilaties of medicine. New York: Milbank Memorial Fund, 1999.

16. Haas B, Gotlib Conn L, Rubenfeld GD, et al. "It's Parallel Universes": An Analysis of Communication Between Surgeons and Intensivists. Crit Care Med 2015;43:2147-54.

17. Molmenti EP, Dunn GP. Transplantation and palliative care: the convergence of two seemingly opposite realities. Surg Clin North Am 2005;85:373-82.

18. Dunn GP. Restoring palliative care as a surgical tradition. Bull Am Coll Surg 2004;89:23-9.

19. Dunn GP. Surgical palliative care: an enduring framework for surgical care. Surg Clin North Am 2005;85:169-90.

20. Surgeons Palliative Care Workgroup. Office of Promoting Excellence in End-of-Life Care: Surgeon's Palliative Care Workgroup report from the field. J Am Coll Surg 2003;197:661-86.

21. Dunn GP. Surgery, palliative care, and the American College of Surgeons. Ann Palliat Med 2015;4:5-9.

22. Surgical Palliative Care: A Resident's Guide. Chicago, IL: American College of Surgeons Cuniff-Dixon Foundation, 2009.

23. Kamal AH, Bull JH, Swetz KM, et al. Future of the Palliative Care Workforce: Preview to an Impending Crisis. Am J Med 2017;130:113-4.

24. Kamal AH, Bull J, Wolf S, et al. Characterizing the Hospice and Palliative Care Workforce in the U.S.: Clinician Demographics and Professional Responsibilities. J Pain Symptom Manage 2016;51:597-603.

25. Kamal AH, Maguire JM, Meier DE. Evolving the Palliative Care Workforce to Provide Responsive, Serious Illness Care. Ann Intern Med 2015;163:637-8.

26. The Surgical Palliative Care Podcast. Available online: https://thesurgicalpalliativecarepodcast.buzzsprout.com/

27. Weissman DE, Block SD. ACGME requirements for end-of-life training in selected residency and fellowship programs: a status report. Acad Med 2002;77:299-304.

28. Larrieux G, Wachi BI, Miura JT, et al. Palliative Care Training in Surgical Oncology and Hepatobiliary Fellowships: A National Survey of Program Directors. Ann Surg Oncol 2015;22 Suppl 3:S1181-6.

29. DeVita MA, Arnold RM, Barnard D. Teaching palliative care to critical care medicine trainees. Crit Care Med 2003;31:1257-62. 
30. Carmody S, Meier D, Billings JA, et al. Training of palliative medicine fellows: a report from the field. J Palliat Med 2005;8:1005-15.

31. Lilley EJ, Cooper Z, Schwarze ML, et al. Palliative Care in Surgery: Defining the Research Priorities. Ann Surg 2018;267:66-72.

32. Lilley EJ, Cooper Z, Schwarze ML, et al. Palliative Care in Surgery: Defining the Research Priorities. J Palliat Med 2017;20:702-9.

33. Surgical Palliative Care. New York, NY: Oxford University Press, 2019.

34. SPC Society. Available online: https://spcsociety.org/

35. Bishop JP. The Anticipatory Corpse: Medicine, Power, and the Care of the Dying. Notre Dame, IN: University of Notre Dame Press, 2011.

Cite this article as: McCammon SD, Hoffman MR. Development of surgical palliative care as a field and community building in palliative care: past, present, and future directions. Ann Palliat Med 2022;11(2):852-861. doi: 10.21037/apm-21-373
36. Field D. Palliative medicine and the medicalization of death. Eur J Cancer Care (Engl) 1994;3:58-62.

37. Conrad P. The Medicalization of Society: On the Transformation of Human Conditions into Treatable Disorders. Baltimore, MD: The Johns Hopkins University Press, 2007.

38. Bradshaw A. The spiritual dimension of hospice: the secularization of an ideal. Soc Sci Med 1996;43:409-19.

39. Quill TE, Abernethy AP. Generalist plus specialist palliative care--creating a more sustainable model. N Engl J Med 2013;368:1173-5.

40. Quill TE, Cassel CK. Nonabandonment: a central obligation for physicians. Ann Intern Med $1995 ; 122: 368-74$. 